\title{
Seroprevalencia de anticuerpos IgG contra parvovirus B19 en donantes de sangre de hospitales en Santiago, Chile
}

\author{
Aldo Gaggero'a , Joselin Rivera ${ }^{1 b}$, Elizabeth Calquín ${ }^{1 b}$, \\ Carmen E Larrañaga ${ }^{1}, 0$ scar León ${ }^{1 c}$, Patricia Díaz ${ }^{2}$, \\ Nicolás G aggero ${ }^{1 d}$. \\ Seroprevalence of IgG antibodies \\ against parvovirus $B 19$ among blood \\ donors from Santiago, Chile
}

Background: Parvovirus B19 (B19) is associated with a wide range of disease manifestations, whose severity depends on the immunological and hematological status of the host. Infection with B19 has been reported worldwide and the prevalence of immunoglobulin $\mathrm{G}$ antibodies against B19 increases with age and varies by location and time of the last B19 epidemic. Aim: To evaluate the prevalence of IgG antibodies against Parvavirus B19 virus in a population of volunteer blood donors at two hospital blood banks in Santiago, Chile. Material and Methods: A total of 400 serum samples from blood donors aged 18 to 65 years, were examined for the presence of IgG antibodies against Parvovirus B19. Results: The overall prevalence of IgG antibodies was $54.8 \%$. No significant difference was found between men and women (57.6\% and $49.3 \%$, respectively). Conclusions: IgG antibody seroprevalence against Parvovirus B19, was 55\% in this sample of Chilean blood donors. This figure is in agreement with previous reports from abroad (Rev Méd Chile 2007; 135: 443-8).

(Key words: Blood donors; Immunoglobulin G; Parvovirus B19, human)

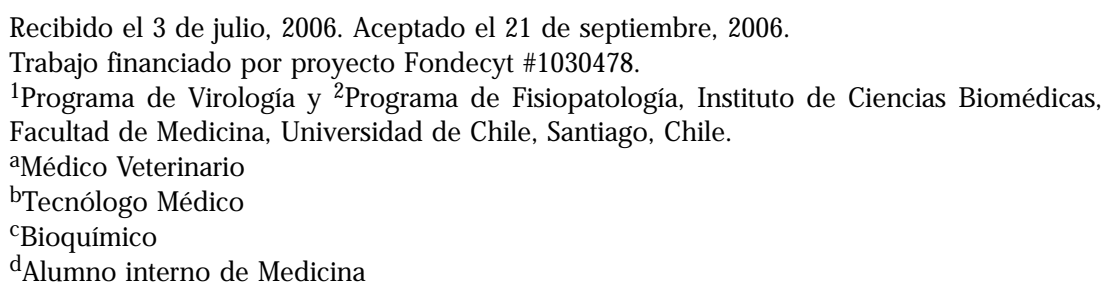

$P^{a}$ arvovirus B19 (B19) se asocia a un amplio rango de manifestaciones clínicas, cuya severidad depende del estado inmunológico y hemato-

Correspondencia a: Dr. Aldo Gaggero. Programa de Virología, ICBM, Facultad de Medicina, Universidad de Chile. Independencia 1027. Santiago, Chile. E mail: agaggero@med.uchile.cl lógico del hospedero ${ }^{1}$. En individuos inmunocompetentes, la manifestación más común de la infección por Parvovirus B19 es el eritema infeccioso, o también llamada quinta enfermedad. En individuos con desórdenes hematológicos subyacentes, tales como anemia de células en hoz (sickle cell disease), la infección con el virus puede dar 
lugar a crisis aplástica. A su vez, la infección durante embarazo puede causar hydrops fetalis y aborto espontáneo. Anemia, aplasia de células rojas y artropatías pueden ocurrir en pacientes inmunocomprometidos que presentan infección crónica con el virus ${ }^{2,3}$. Los anticuerpos IgM específicos se producen en el transcurso de la segunda semana posterior a la infección y son detectables durante 4 a 6 meses y a veces por más tiempo. Por otra parte, los anticuerpos del tipo IgG aparecen alrededor de 7 días después que la $\operatorname{IgM}$, pueden persistir por años y su presencia generalmente es signo de infección pasada 4 . La infección por B19 es cosmopolita y la prevalencia de IgG aumenta con la edad y varía según la localización geográfica y el periodo desde el último brote epidémico de la enfermedad. En Japón, la seropositividad en grupos menores de 20 años corresponde a $20 \%$ y en grupos mayores de 60 años de edad es de $80 \% 5$. En Inglaterra y Gales, la tasa de seropositividad es $5 \%$ a $15 \%$ en niños de $1-5$ años, $50 \%$ a $60 \%$ en adolescentes y adultos jóvenes, y más de $85 \%$ en grupos sobre 70 años de edad ${ }^{6}$. En los Estados Unidos de Norteamérica, la seroprevalencia es de $2 \%$ en niños menores de 5 años y de $50 \%$ en los adultos mayores de 20 años ${ }^{7}$. En Brasil, se ha observado una prevalencia de IgG de $35 \%$ en niños menores de 5 años, mientras que en casi $80 \%$ en niños de 11 a 15 años y $90 \%$ en adultos sobre 50 años $^{8}$. En un estudio previo en Chile, anticuerpos IgG anti-B19 fueron determinados en 730 individuos sanos entre 1 y 35 años de edad. En esa población, la tasa de positividad para IgG fue de $21 \%$ en los niños menores de 5 años, alcanzando $60 \%$ en los adultos jóvenes 9 .

Las vías de transmisión de Parvovirus B19 han sido bien establecidas. $\mathrm{Si}$ bien la ruta respiratoria constituye la principal vía de transmisión, el virus se puede transmitir también vía vertical y mediante transfusiones de sangre y hemoderivados. Existe creciente preocupación por esta última forma de transmisión, especialmente cuando el receptor de la transfusión es un inmunocomprometido, donde la infección por Parvovirus B19 puede provocar serias complicaciones, especialmente hematológicas ${ }^{2,3}$.

En Chile no se conoce el comportamiento de la infección por Parvovirus B19 a distintas edades. A su vez, existe muy poca información de la seroprevalencia de este virus en distintos individuos y especialmente en población de donantes de sangre, como también estudios que determinen con qué frecuencia se encuentra el virus infectivo en esta particular población de individuos. Finalmente no existe información nacional respecto del impacto que esta infección viral tiene sobre diferentes cuadros clínicos que se asocian a la infección por este virus en distintos grupos de personas.

El propósito de este estudio fue determinar la presencia de anticuerpos IgG anti-B19, en una población de donantes de sangre voluntarios que acuden a los bancos de sangre de dos hospitales en Santiago de Chile, para conocer la seroprevalencia de esta infección en esta población en particular. Este estudio corresponde a una primera etapa de una línea de investigación en desarrollo en nuestro laboratorio.

\section{Material y MÉTOdo}

Muestras. Muestras de plasma de 400 donantes voluntarios de sangre (rango de edad entre $18 \mathrm{y}$ 65 años) fueron obtenidas entre abril y julio de 2003, desde los bancos de sangre de los hospitales José Joaquín Aguirre y del Salvador, en Santiago. Estas incluyeron 129 muestras en el intervalo de edad de 18-27 años, 131 entre 28-37 años, 92 en el grupo de 38-47 años y 48 en el grupo de $>48$ años de edad (Tabla 1). Las muestras de suero fueron mantenidas a $-70^{\circ} \mathrm{C}$ hasta su uso.

El presente estudio fue llevado a cabo con la aprobación del Comité de Etica de la Facultad de Medicina de la Universidad de Chile.

Detección de IgG anti Parvovirus B19. Para determinar la presencia de anticuerpos IgG anti-B19, se empleó el kit comercial Parvovirus B19 IgG DxSelect ${ }^{\mathrm{TM}}$ assay (Focus Diagnostics, USA), que fue utilizado según las instrucciones del fabricante. Este ensayo de inmunoanálisis (ELISA), detecta anticuerpos contra la proteína viral recombinante VP1, que es usada como antígeno en la reacción. Brevemente, las muestras diluidas de suero y los controles se incubaron en los pocillos para permitir que el anticuerpo específico presente en las muestras reaccionara con el antígeno viral. Posterior al lavado, se agregó IgG anti humana conjugada con peroxidasa, la cual reacciona con la IgG presente en las muestras. El exceso de conjugado 
Tabla 1. D istribución de los donantes en ambos bancos de sangre por edad y sexo

\begin{tabular}{|lccc|}
\hline Edad (años) & $\begin{array}{c}\text { Hombres } \\
\text { N (\%) }\end{array}$ & $\begin{array}{c}\text { Mujeres } \\
\text { N }(\%)\end{array}$ & $\begin{array}{c}\text { Total donantes } \\
\text { N }(\%)\end{array}$ \\
\hline $18-27$ & $88(33,3)$ & $41(30,2)$ & $129(32,2)$ \\
$28-37$ & $82(31,1)$ & $49(36,0)$ & $131(32,8)$ \\
$38-47$ & $63(23,9)$ & $29(21,3)$ & $92(23,0)$ \\
$>48$ & $31(11,7)$ & $17(12,5)$ & $48(12,0)$ \\
Total & 264 & 136 & 400 \\
\hline
\end{tabular}

fue eliminado mediante lavado y se añadió sustrato, permitiendo posteriormente el cambio de color. Una vez detenida la reacción, se determinó la absorbancia a $450 \mathrm{~nm}$. Las lecturas de la densidad óptica de las muestras se compararon con los controles de referencia y se interpretaron los resultados como positivos, negativos o ambiguos, según los valores de corte recomendados por el fabricante.

Estadística. Las diferencias de la edad y sexo fueron determinadas por la prueba de $\mathrm{z}$ y los datos categóricos fueron analizados usando la prueba del chi-cuadrado. Todas las comparaciones fueron duales y un valor de $\mathrm{P}$ inferior o igual 0,05 fue considerado como significativo.

\section{RESULTADOs}

De las 400 muestras de suero analizadas, 252 fueron colectadas en el banco de sangre del Hospital José Joaquín Aguirre y 148 en el banco de sangre del Hospital del Salvador. La distribución por edad y sexo de los donantes se muestra en la Tabla 1. La distribución por edad no fue significativamente diferente entre hombres y mujeres $(p=0,740)$. La prevalencia de IgG anti-B19 en el total de las muestras fue de $54,8 \%$ (Tabla 2) y no se detectaron diferencias significativas entre hombres y mujeres (57,6\% y $49,3 \%$, respectivamente). Por otra parte, no se observaron diferencias significativas entre ambos bancos de sangre (56,0\% en el Hospital de José Joaquín Aguirre y $52,7 \%$ en el Hospital del Salvador) ( $p=0,592$ ).

Comparando por género dentro de cada rango de edad, la seroprevalencia en hombres fue más alta, pero no estadísticamente significativa, en todos los grupos de edad (Tabla 3 y Figura 1). En los varones, la prevalencia de IgG aumentó con edad hasta el rango de 38-47 años (60,3\%), para disminuir a 54,8\% en el grupo de mayores de 48 años. En las mujeres, se observó un aumento solamente hasta los $28-37$ años $(57,1 \%)$ y luego fue disminuyendo paulatinamente a $41,4 \%$ en el intervalo de 38-47 años y a 35,3\% en el grupo de mayores de 48 años. Aunque no se encontró ninguna relación significativa entre la prevalencia de IgG y la edad en hombres y mujeres en todos los grupos de edad ( $p=0,410)$, se aprecia una

Tabla 2. Prevalencia de IgG anti-B 19 en los donantes de sangre

\begin{tabular}{|lcc|}
\hline Banco de Sangre & & \\
Hospital & Muestras & IgG positiva (\%) \\
\hline José Joaquín Aguirre & 252 & $141(56,0)$ \\
Salvador & 148 & $78(52,7)$ \\
Total & 400 & $219(54,8)$ \\
\hline
\end{tabular}

$\mathrm{p}=0,592$. 
Tabla 3. D istribución de los donantes IgG anti-B19 positivos en ambos bancos de sangre por edad y sexo

\begin{tabular}{|lcrr|}
\hline Edad (años) & Hombres & Mujeres & Total donantes \\
& N $(\%)$ & N $(\%)$ & N $(\%)$ \\
\hline $18-27$ & $50(56,8)$ & $21(51,2)$ & $71(55,0)$ \\
$28-37$ & $47(57,3)$ & $28(57,1)$ & $75(57,3)$ \\
$38-47$ & $38(60,3)$ & $12(41,4)$ & $50(54,3)$ \\
$>48$ & $17(54,8)$ & $6(35,3)$ & $23(47,9)$ \\
Total & $152(57,6)$ & $67(49,3)$ & $219(54,8)$ \\
\hline
\end{tabular}

$\mathrm{p}=0,410$.

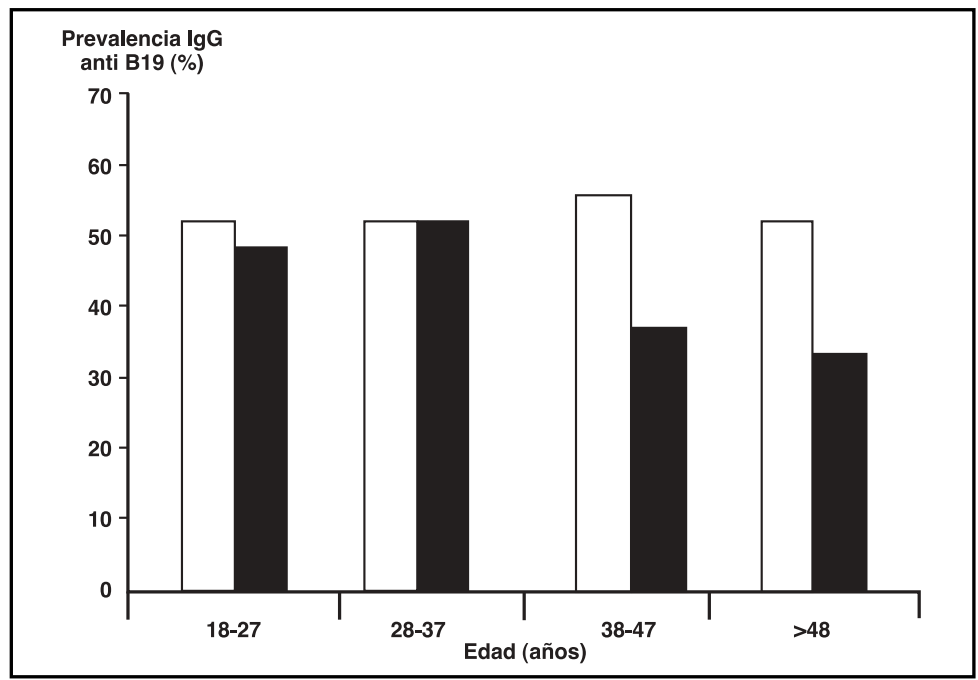

Figura 1. Prevalencia de IgG anti-B19 en donantes de sangre, estratificados por edad y sexo $\square$, Hombres; $\mathbf{\square}$, Mujeres.

diferencia entre hombres y mujeres en los grupos de edad de 38-47 años (60,3 versus $41,3 \%$ respectivamente, $\mathrm{p}=0,411)$ y los grupos $>48$ años $(54,8$ versus $35,3 \%$ respectivamente, $\mathrm{p}=0,729$ ).

\section{Discusión}

Parvovirus B19 es un virus cosmopolita, que infecta de manera frecuente al hombre y cuya primoinfección ocurre generalmente en la niñez, lo que se traduce en que un alto porcentaje de la población presenta anticuerpos contra el virus. La presencia de anticuerpos del tipo IgG anti-B19 se detecta en rangos entre $2 \%-15 \%$ en niños de 1 a 5 años, 15\% a $60 \%$ en niños de 6 a 19 años, 30\% a $60 \%$ en adultos, y en más de $85 \%$ en la población geriátrica ${ }^{1}$. Estudios en diversos países desarrollados señalan índices similares de seropositividad $6,10-12$. Sin embargo, en países en vías de desarrollo en Sudamérica y Africa, la seroprevalencia encontrada ha sido levemente mayor, posiblemente indicando una transmisión más alta del virus en condiciones de pobreza ${ }^{8,13}$.

La prevalencia de IgG anti-B19 en muestras de suero colectadas en donantes de sangre de 18 a 65 años desde dos bancos de sangre en Santiago fue de 54,8\%. Esta seroprevalencia indica que una gran cantidad de individuos muestra exposición previa al virus. Cuando la presencia de IgG antiB19 fue estudiada en hombres y mujeres por separado, la seroprevalencia fue de $57,6 \%$ en hombres y $49,3 \%$ en mujeres y no mostró diferencia significativa. 
En diversos estudios, se ha observado que la prevalencia de IgG en mujeres es más alta que en varones $^{14,15}$ y contrariamente en otros $8,9,16,17$, así como en el presente estudio, se ha demostrado que no hay diferencias significativas entre ambos sexos.

La seroprevalencia en hombres fue más alta, pero no estadísticamente significativa, en todos los grupos de edad estudiados. En esta serie se observó una disminución de la seroprevalencia de IgG en los donantes mayores de 48 años, lo que difiere con otros estudios, en los cuales se reporta un incremento constante con la edad. Esta diferencia puede deberse al menor número de donantes enrolados en el grupo de individuos mayores de 48 años.

$\mathrm{Si}$ bien la prevalencia de IgG anti-B19 fue alta en los donantes de sangre (54,8\%), hubo un porcentaje importante en el grupo de las mujeres hasta 47 años (cercano a 50\%), que no poseen anticuerpos protectivos y, por lo tanto, son susceptibles a la infección por el virus. Abarca et al, estimaron que alrededor de 300 muertes fetales en Chile cada año podrían ser debido a la infección por este virus ${ }^{9}$. Sin embargo, muchos casos de hydrops fetalis en nuestro país no son diagnosticados, lo que haría subestimar la mortalidad por esta enfermedad. Estudios adicionales son necesarios para establecer el real impacto de la infección materna por Parvovirus B19 en nuestro país.

Aunque el genoma de Parvovirus B19 se encuentra en las secreciones respiratorias durante la viremia, sugiriendo que la transmisión de la infección es principalmente por vía respiratoria, el virus se puede también transmitir por la sangre y sus derivados. Diversos estudios han evaluado el riesgo de la transmisión mediante productos sanguíneos, debido a que varios procedimientos de inactivación del virus, como son tratamientos térmicos o el uso de detergentes, parecen ser ineficaces. Tres estudios recientes realizados en donantes de plasma y en muestras de suero de donantes sanguíneos, demostraron una prevalencia de ADN de B19 detectado

\section{REFERENCIAS}

1. Heegaard ED, Brown KE. Human Parvovirus B19. Clin Microbiol Rev 2002; 15: 485-505.

2. Young NS, Brown KE. Parvovirus B19. N Engl J Med 2004; 350: 586-97.

3. Corcoran A, Doyle S. Advances in the biology, por la reacción en cadena de la polimerasa (PCR) de 1:625, $1: 800$ y 1:3915, respectivamente ${ }^{18-20}$.

La detección de donantes de sangre con viremia es importante, si se transfunde a mujeres embarazadas susceptibles o a pacientes inmunocomprometidos, en los cuales la infección con B19 puede tener serias consecuencias. El hecho que anticuerpos IgM o IgG puedan estar ausentes en donantes con alta viremia, indica que la detección de anticuerpos podría no ser una estrategia efectiva para reducir la transmisión a través de productos sanguíneos ${ }^{19}$. En estos casos, la pesquisa de genoma viral mediante PCR sería la técnica más adecuada.

En un estudio preliminar, realizado para detec$\operatorname{tar}$ ADN viral en estas muestras de suero, 50 de las 400 (12,5\%) muestras analizadas para IgG anti-B19 fueron estudiadas por una técnica de PCR anidada (datos no mostrados), que se emplea de rutina en nuestro laboratorio ${ }^{21}$. Dos de las muestras fueron positivas por esta técnica (4\%) y fueron negativas para IgM e IgG anti-B19, lo que sugiere que probablemente estas muestras fueron obtenidas durante el período previo a la seroconversión 0 bien, desde individuos portadores crónicos sin anticuerpos detectables. La prevalencia de ADN viral en este grupo pequeño de muestras analizadas por PCR fue mayor a lo reportado en otros estudios similares ${ }^{18-20,22,23}$. Estos resultados sugieren que estudios adicionales deben ser realizados, para estimar la prevalencia de ADN de B19 en donantes de sangre chilenos y por tanto, evaluar el riesgo de transmisión por esta vía en la población.

La prevalencia de IgG anti-B19 de 54,8\%, determinada en donantes de la región metropolitana, está en concordancia a lo reportado en estudios previos en población adulta del Reino Unido, Estados Unidos de Norteamérica, Italia y de otros países desarrollados 1,6,16,23-25. Esta seroprevalencia indica que una importante cantidad de individuos muestran exposición previa al virus.

diagnosis and host-pathogen interactions of Parvovirus B19. J Med Microbiol 2004; 53: 459-75.

4. Anderson MJ, Lewis E, Kidd IM, Hall SM, Cohen BJ. An outbreak of erythema infectiosum associated with human Parvovirus infection. J Hyg (London) 1984; 93: 85-93.

5. Yamashita $K$, Matsunaga $Y$, Taylor-Wiedeman J, 
YAMAZAKI S. A significant age shift of the human Parvovirus B19 antibody prevalence among young adults in Japan observed in a decade. Jap J Med Sci Biol 1992; 45: 49-58.

6. Cohen BJ, Buckiey MM. The prevalence of antibody to human Parvovirus B19 in England and Wales. J Med Microbiol 1988; 25: 151-3.

7. Anderson LJ, Tsou C, Parker RA, Chorba TL, WulfF $\mathrm{H}$, Tattersall $\mathrm{P}$ et al. Detection of antibodies and antigens of human Parvovirus B19 by enzyme linked immunoabsorbent assay. J Clin Microbiol 1986; 24: 522-6.

8. Nascimento JP, Buckiey MM, Brown KE, Cohen BJ. The prevalence of antibody to human Parvovirus B19 in Rio de Janeiro, Brazil. Rev Inst Med Trop Sao Paulo 1990; 32: 41-5.

9. Abarca K, Cohen BJ, Vial P. Seroprevalence of Parvovirus B19 in urban Chilean children and young adults, 1990 and 1996. Epidemiol Infect 2002; 128: 59-62.

10. ANDERSON LJ. Role of Parvovirus B19 in human disease. Pediatr Infect Dis J 1987; 6: 711-8.

11. Courouce AM, Ferchal F, Morinet F, Muler A, Drouet J, Souler JP et al. Human parvovirus infections in France. Lancet 1984; 1: 160.

12. Nunoue T, Окосhi K, Mortimer PP, Cohen BJ. Human parvovirus (B19) and erythema infectiosum. J Pediatr 1985; 107: 38-40.

13. Tolfuenstam T, Enbom M, Ghebrekidan H, Ruden U, Linde A, GRandien M et aL. Seroprevalence of viral childhood infections in Eritrea. J Clin Virol 2000; 16: 49-54.

14. Lin KH, You SL, Chen CJ, Wang CF, Yang CS, YAMAZAKI S. Seroepidemiology of human Parvovirus B19 in Taiwan. J Med Virol 1999; 57: 169-73.

15. De Freitas RB, Wong D, Boswell F, De Miranda MF, Linhares AC, Shirley J et al. Prevalence of human parvovirus (B19) and rubella virus infections in urban and remote rural areas in northern Brazil. J Med Virol 1990; 32: 203-8.

16. Manaresi E, Gawinela G, Morsem Labate AM, Zucche山 P, Zaccarew D, Ambretti $S$ et al. Seroprevalence of IgG against conformational and linear capsid antigens of Parvovirus B19 in Italian blood donors. Epidemiol Infect 2004; 132: 857-62.

17. Kelly HA, Siebert D, Hammond R, Leydon J, Kiely P, MAsKILL W. The age-specific prevalence of human parvovirus immunity in Victoria, Australia compared with other parts of the world. Epidemiol Infect 2000; 124: 449-57.

18. Weimer T, Streichert S, Watson C, Groner A. Hightiter screening PCR: a successful strategy for reducing the Parvovirus B19 load in plasma pools for fractionations. Transfusion 2001; 41: 1500-4.

19. Hitzier WE, Runkel S. Prevalence of human Parvovirus B19 in blood donors as determined by a haemagglutination assay and verified by the polymerase chain reaction. Vox Sang 2002; 82: 18-23.

20. Thomas I, Di Giambattista M, Gerard C, Mathys E, Hougardy V, Latour B et al. Prevalence of human erythrovirus B19 DNA in healthy Belgian blood donors and correlation with specific antibodies against structural and non-structural viral proteins. Vox Sang 2003; 84: 300-7.

21. Durigon EL, ERdman DD, Gary GW, Paliansch MA, TOROK TJ, ANDERSON LJ. Multiple primer pairs for Polymerase chain reaction (PCR) amplification of human Parvovirus B19 DNA. J Virol Methods 1993; 44: 155-65.

22. Jordan J, Tiangco B, Kiss J, Koch W. Human Parvovirus B19: prevalence of viral DNA in volunteer blood donors and clinical outcomes of transfusion recipients. Vox Sang 1998; 75: 97-102.

23. Wakamatsu C, Takakura F, Kojima E, Kiriyama $Y$, Goto N, Matsumoto K et al. Screening of blood donors for human Parvovirus B19 and characterization of the results. Vox Sang 1999; 76: 14-2.

24. Tsujimura M, Matsushita $K$, Shiraki $H$, Sato $H$, Окосні K, Maeda Y. Human Parvovirus B19 infection in blood donors. Vox Sang 1995; 69: 206-12.

25. Candotti D, Etiz N, Parsyan A, Aluin JP. Identification and Characterization of Persistent Human Erythrovirus Infection in Blood Donor Samples. J Virol 2004; 23: 12169-78.

Agradecimientos

Agradecemos a la Dra. Lucía Toriello, Jefe del Banco de Sangre del Hospital Salvador y al Dr. Milton Larrondo, Jefe del Banco de Sangre del Hospital Clínico José Joaquín Aguirre, por permitir la obtención de las muestras de suero. A Rosa Corvalán por su excelente asistencia técnica. 